\title{
APROXIMACIÓN AL CONOCIMIENTO DE LAS PRIMERAS REALIZACIONES EN EL USO DIDÁCTICO DEL CINE EN LA UNIVERSIDAD ESPAÑOLA. NOTICIAS Y TESTIMONIOS
}

\author{
Fernando REDONDO NEIRA
}

Universidad de Santiago de Compostela

El uso del cine con fines didácticos fue objeto de amplios debates y algunas realizaciones a lo largo de los años veinte y treinta en nuestro país. A la par de la consideración intelectual y cultural que el medio cinematográfico iba adquiriendo no sin esfuerzo, surgió también una reivindicación de su utilización al servicio de la enseñanza, de lo cual ha quedado testimonio en artículos en prensa y en revistas especializadas, en libros escritos por pedagogos y en un puñado de disposiciones normativas que trataron de llevar a la práctica algunas facetas de lo que, en aquel tiempo, se consideraba una revolucionaria innovación educativa. El registro y exhibición de imágenes en movimiento pasó a convertirse en un instrumento eficaz para el estudio y la investigación científica, así como para las labores educativas y divulgativas en general.

La institución universitaria participó de todo este movimiento, antes de nada, a través de los primeros y tímidos intentos de convertir al cine en objeto de estudio. Del 27 de febrero al 9 de abril de 1932 se celebró en la Facultad de Filosofía y Letras de la Universidad Autónoma de Barcelona el Curs Universitari de Cinema, considerada la iniciativa pionera en la introducción de la enseñanza del cine en la universidad española. El historiador Caparrós Lera afirma que, con esta experiencia, España se situó en la vanguardia de la docencia del arte fílmico a nivel superior, antes incluso de que esta materia se incorporara a los centros universitarios europeos y norteamericanos ${ }^{1}$. Guillermo Díaz-Plaja fue el director de aquel curso, para el cual contó con diversos especialistas y catedráticos que abordaron aspectos tales como la posición del cine en la

\footnotetext{
${ }^{1}$ José M M CAPARRÓS LERA, "La enseñanza de la Historia del Cine en la Universidad española", en Anthropos, $\mathrm{n}^{\circ}$ 58, 1986. Sobre el mismo tema y del mismo autor puede consultarse: "Guillem Díaz-Plaja, introductor del cinema a la Generalitat", en D'Art, no 11, marzo 1985. El propio DÍAZ-PLAJA comenta esta experiencia en sus Obras selectas. Viejas memorias mías, Barcelona, Carrogio AHR, 1973, p. 55.
} 
teoría del arte, la técnica, la estética y las relaciones del medio fílmico con la educación, la moda, la literatura, la pintura y la música² .

Sobre la incorporación del cine a la actividad académica universitaria habría que anotar la iniciada y nunca concluida tesis doctoral de Gonzalo Menéndez Pidal, a pesar de lo que escribió Luis Gómez Mesa en Nuestro Cinema, donde informaba del éxito de su novedad y de su lectura. Según testimonio del propio Menéndez Pidal, la tesis había sido sugerida por Pedro Salinas y abordaba las relaciones de la literatura, la pintura y, sobre todo, la música, con las imágenes en movimiento ${ }^{3}$.

Conviene situar la utilización del cine en el ámbito universitario en el marco general de cuantos debates se suscitaron en estas primeras décadas del siglo XX acerca de la consideración cultural del cine. Las opiniones divergentes, las posiciones encontradas o las voces a favor y en contra, según se destaquen los aspectos estéticos, industriales o morales, serán un indicio bien claro de la trascendencia social que el medio ha alcanzado. En este sentido, Brian Morris afirma que los filmes soviéticos serán un ejemplo recurrente para afirmar la condición educativa y social del cine ${ }^{4}$. El modelo soviético será constantemente reivindicado por ciertos críticos de izquierda. Veamos sólo un par de ejemplos. El escritor y cineasta anarquista Mateo Santos, director de Popular Film, indica: "Es doloroso que la República no quiera reconocer el alto valor instructivo que para las masas y aun para la minoría intelectual, encierra el cine ruso" . En la misma revista, el futuro cineasta Rafael Gil escribe: "el gobierno de la República debe abrir nuestras fronteras al cinema ruso. Es una medida de cultura y democracia" $"$. Pero, curiosamente, la idoneidad o no de conceder una mayor difusión al cine soviético irrumpirá en esta batalla por conceder una valoración cultural al medio. Con todo, resulta esclarecedor, respecto de este asunto, el propio hecho de que destacadas publicaciones de la época comiencen a dar cabida a los temas cinematográficos. Sería suficiente con recordar la importante presencia del cine en $L a$

\footnotetext{
${ }^{2}$ Esta es al menos la información que aporta José Ma ESCUDERO en Cine español, Madrid, Rialp, 1962, p. 194. DÍAZ-PLAJA elaboró en 1931 un texto en catalán titulado Una cultura del cinema, que serviría de guía para este curso y que será recogido, ya en castellano, en el capítulo Estética del cine mudo, que forma parte de su libro El engaño a los ojos (Notas de estética menor), Barcelona, Destino, 1943.

3 Alfonso PUYAL, "Gonzalo Menéndez Pidal o el cine como documento", en Pedro Poyato Sánchez (coord.), El documental, carcoma de la ficción, X Congreso de la A.E.H.C., Córdoba, Filmoteca de Andalucía, 2004, p. 169.

${ }^{4}$ C. BRIAN MORRIS, La acogedora oscuridad. El cine y los escritores españoles (1920-1936), Córdoba, Junta de Andalucía / Filmoteca de Andalucía, 1993, p. 23.

${ }^{5}$ Mateo SANTOS, "El cinema al servicio de las ideas", en Popular Film, no 257, 16-VII-1931.

${ }^{6}$ Rafael GIL, "Cine documental y educativo", en Popular Film, no 264, 3-IX-1931.
} 
Gaceta Literaria, donde se reúne toda la intelectualidad de la época, con la destacada participación de los miembros del grupo del 27; la sección de crítica "Frente a la pantalla", en la revista España; los textos valorativos que incorpora el diario El Sol desde 1926 a cargo de José Sobrado de Ónega, Focus; determinados ensayos que publica Revista de Occidente, que tratan, generalmente, asuntos de estética y analizan la posición del cine en relación con las vanguardias artísticas ${ }^{7}$.

Este es, por tanto, el contexto que los citados debates en torno al cine utilizado con fines didácticos, incluyendo, por supuesto, lo realizado en el campo universitario y que, a su vez, resulta revelador respecto de la incorporación del medio fílmico a los discursos de la cultura. El entusiasmo suscitado por este novedoso método de educación es una constante que se repite en todas las voces que reclaman una mayor atención a las posibilidades pedagógicas del cine. El pedagogo Blanco Castilla destaca algunas virtudes de la películas que las hace especialmente recomendables para estos fines. Se refiere al poder de sugestión del cine, que activa la imaginación y la memoria: “Apoyándose en el interés, en la fuerza de sugestión, en la simpatía, en el entusiasmo, desarrolla la observación, la curiosidad sana, la iniciativa, la investigación y el amor puro a la verdad",

El gran crítico e historiador Luis Gómez Mesa se cuenta entre los mayores defensores del cine educativo. Formó parte del Comité Español de Cinema Educativo, constituido en 1930, adscrito al Instituto de Cultura Social (del Ministerio de Trabajo) y creado, en realidad, para ostentar en España la representación del Instituto Internacional de Cinema Educativo9. Integraron este comité, junto a gente del cine como el propio

\footnotetext{
${ }^{7}$ Merece la pena destacar algunos de esos ensayos: Guillermo DE TORRE, "Cinema", en Revista de Occidente, $\mathrm{n}^{\mathrm{0}}$ 34, abril, mayo, junio 1926; Fernando VELA, "Desde la ribera oscura (para una estética del cine)", en Revista de Occidente, $\mathrm{n}^{\circ}$ 23, mayo 1925, incluido en el libro El arte al cubo y otros ensayos, Madrid, Cuadernos Literarios, 1927. Antonio ESPINA, "Reflexiones sobre cinematografía", en Revista de Occidente, T. XV, enero, febrero, marzo, 1927, artículo incorporado posteriormente al libro Lo cómico contemporáneo y otros ensayos, Madrid, Cuadernos Literarios, 1928.

${ }^{8}$ F. BLANCO CASTILLA, El cinema educativo y Gracián pedagogo, Madrid, Francisco Beltrán, 1933, p. 19. Habría que destacar también el hecho de que se edite en este momento una publicación periódica dedicada, exclusivamente, al cine educativo: Acción Cultural Cinegráfica.

${ }^{9}$ El Instituto Internacional de Cinema Educativo (I.C.E.) había sido creado en 1928 por el gobierno italiano para ser adscrito a continuación al Instituto Internacional de Cooperación de la Sociedad de Naciones. Su función primordial será el fomento de la producción y difusión de filmes pedagógicos, facilitando su libre circulación. En 1934 celebró el Primer Congreso Internacional de Cinematografía de Educación y Enseñanza, al que acudió Giménez Caballero, y que tuvo por objeto conocer las relaciones del cine con la enseñanza y elaborar planes para el futuro. Además, desde 1929, el I.C.E. edita en cinco idiomas la Revista Internacional de Cinema Educativo. Puede consultarse más información sobre este organismo en un libro de la época: M.F. ALVAR, Cinematografía pedagógica y educativa, Madrid, J.M. Yagües, 1936. También en este otro artículo posterior: Miguel HERRERO ORTIGOSA, "El cine pedagógico en el mundo", en Revista Española de Pedagogía, nº 34, abril-junio 1951.
} 
Gómez Mesa, Fernando G. Mantilla, José Val del Omar y Ricardo Urgoiti, pedagogos, científicos e intelectuales de la talla de Gregorio Marañón, Alberto Jiménez Fraud, Fernando de los Ríos o Lorenzo Luzuriaga, entre otros. Ernesto Giménez Caballero fue su secretario y a él se deben las pocas realizaciones llevadas a cabo: elaboración de un catálogo de títulos utilizables en las escuelas y algunas exhibiciones de tipo popular ${ }^{10}$.

El pedagogo belga Alexis Sluys está considerado el pionero en el empleo del cine como instrumento didáctico. Director honorario de la Escuela Normal de Bruselas, presidente de la Escuela Superior de Pedagogía y de la Liga de la Enseñanza, relata sus experiencias en un libro que sería editado en castellano en 1925: "Convencidos, desde el punto de vista pedagógico, de la utilidad del empleo del cinematógrafo para la enseñanza y educación, organizamos el 23 de septiembre de 1908 una sesión demostrativa en la Escuela Normal de Bruselas, la primera aplicación escolar de la cinta

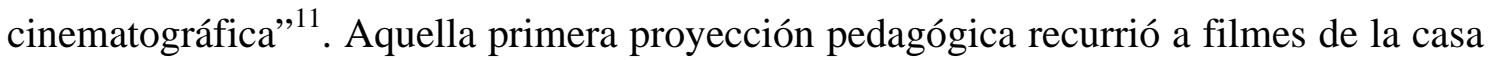
francesa Gaumont con imágenes del Nilo y de los monumentos de la Grecia clásica. No obstante, otras fuentes citan a otros pioneros, como es el caso del médico (y cineasta, al menos ocasional, según estas noticias) Eugéne Louis Doyene: "Fue el primero en percibir las excepcionales dotes pedagógicas de aquel juguete a quien ningún hombre de prestigio en el campo de la ciencia le concedía la más mínima beligerancia y consecuentemente con su idea, filmó, en 1899, la primera película pedagógica [...] su contenido fue ni más ni menos que una operación quirúrgica"12.

Como puede comprobarse, el cine educativo estuvo, en sus inicios, en manos de científicos o pedagogos, que destacaban la funcionalidad del medio, su aprovechamiento como herramienta didáctica que favoreciera el aprendizaje con la visión directa de los fenómenos objeto de estudio. Pedagogo era también M. F. Alvar, quien había sido becado por la Junta para la Ampliación de Estudios y por la Dirección de Enseñanza Profesional y Técnica, del Ministerio de Instrucción Pública, para estudiar

\footnotetext{
${ }^{10}$ Estas y otras informaciones sobre el desarrollo del cine educativo proceden del libro de GÓMEZ MESA, España en el mundo sin fronteras del cinema educativo, Madrid, Unión Iberoamericana, 1935. Sobre legislación y todo tipo de disposiciones normativas encaminadas al fomento del cine educativo, puede consultarse un estudio muy completo en: María del Mar DEL POZO ANDRÉS, "El cine como medio de alfabetización y de educación popular. Primeras experiencias", en Sarmiento. Anuario Galego de Historia da Educación, nº 1, 1997.

${ }_{11}^{11}$ Alexis SLUYS, Cinematografía escolar y post-escolar, Madrid, Ed. de la Lectura, 1925, p. 7.

${ }_{12}$ Miguel HERRERO ORTIGOSA, op. cit. El doctor Doyene es también mencionado por Ysmael Álvarez Rodríguez, quien además cita a Jean Comandon, otro científico que con la ayuda de Charles Pathé filmó numerosas películas de bacteriología, parasitología y hematología. Ver: Ysmael ÁLVAREZ RODRÍGUEZ, "Cine científico", en VV. AA., Historia del cortometraje español, Alcalá de Henares, Festival de Cine de Alcalá de Henares, 1996, p. 492.
} 
la cinematografía educativa en el extranjero. De sus investigaciones surgió el libro, ya citado aquí, Cinematografía pedagógica y educativa. Alvar distingue entre filme educativo, filme cultural y filme pedagógico. Este último se destina exclusivamente a la enseñanza escolar, superior, orientación profesional, técnica e investigación científica. Precisamente sobre educación superior e investigación, afirma que el cine ha favorecido el estudio a través del uso del ralentí o de la microcinematografía ${ }^{13}$. Las tomas de vistas microscópicas serán muy útiles, por ejemplo, para la realización de filmes biológicos, que recurren a los acelerados y a los ralentíes. Alvar informa también acerca del uso habitual del cinematógrafo en la Facultad de Medicina de Madrid ${ }^{14}$.

Por lo que se desprende de distintos testimonios, el cine llegó a la universidad, en buena medida, de la mano de los filmes científicos. Ya en 1927, en la primera de las sesiones cineclubistas organizadas por Buñuel en la Residencia de Estudiantes, se proyectaron ciertos materiales fílmicos que podríamos considerar encuadrables en el cine científico, por el uso de técnicas tan del gusto de aquel como el mencionado ralentí. Bajo el título genérico de "Cinematógrafo de lo invisible", se presentaron, según consta en el programa de mano citado por Román Gubern, una serie de "movimientos ultrarrápidos imperceptibles para el ojo, recogidos por M. Lucien Bull, subdirector del Instituto Marey" ${ }^{\prime 15}$. Pero fue en el Cine Club Español, auspiciado, como es sabido, por Ernesto Giménez Caballero desde La Gaceta Literaria, donde se dieron a conocer las películas del que está considerado el máximo exponente del cine científico en esta época. Se trata de Jean Painlevé, cuyas películas Les Owrins, Bernard L'ermité y Hyas se exhibieron en la sesión de mayo de 1930 y fueron presentadas por Gregorio Marañón. Gómez Mesa escribió con admiración de los filmes de este renombrado director de su tiempo: "Le basta dirigir su vista y su actividad a lo más minúsculo -y admirable- de la fauna y flora de los mares, para superar las obras de fantasía"16.

La relación mutua entre cine y ciencia se remonta, por tanto, a estas primeras décadas del siglo XX. En los años de la República, y si hablamos de la introducción del cine en la universidad, hay que hablar necesariamente de Guillermo Fernández Zúñiga.

\footnotetext{
${ }^{13}$ M.F. ALVAR, op. cit., pp. 7 y ss.

${ }^{14}$ Ibídem, p. 36.

${ }^{15}$ Román GUBERN, Proyector de luna. La generación del 27 y el cine. Barcelona, Anagrama, 1999, p. 261.

${ }^{16}$ Citado en José ARMIDA SOTILLO, "Luis Buñuel, Giménez Caballero y el Cine Club de La Gaceta Literaria", en Turia, n⿳ 20, junio 1992. Otra crítica de GÓMEZ MESA sobre esta misma sesión del Español apareció en el $\mathrm{n}^{\circ} 83$ de La Gaceta Literaria (1-VI-1930), donde señala que las películas de Painlevé están al servicio de la ciencia y que son auténticamente aleccionadoras.
} 
En la universidad madrileña compartió estudios (Biología) y vocación cinematográfica con otro cineasta de esta época, que destacaría poco después como documentalista: Carlos Velo. Así relata Zúñiga sus inicios en el cine científico: "Cuando todavía era estudiante de Biología, en 1932, realicé ayudado por el cineasta Carlos Velo una película sobre insectos sociales: abejas y hormigas. En el Instituto donde trabajaba había una colmena de cristal, abierta, que yo había diseñado, y hormigueros artificiales" ${ }^{\text {17 }}$. En cuanto a Velo, ha quedado registrado para la historia que a él se debe la primera lectura de una tesis doctoral acompañada de una proyección cinematográfica, al menos la primera de la que se tiene noticia. Se trataba de demostrar ciertas teorías acerca de la comunicación de las abejas, culminando así las investigaciones con los insectos sociales que había compartido con Zúñiga. A este respecto existen múltiples testimonios. En primer lugar del propio Velo. Recordemos algunas de sus afirmaciones más significativas: "Con Guillermo Zúñiga conseguimos una cámara Kodak [...] Montamos la cámara de 16 milímetros, con tele, en el microscopio. Aumenté, así, la potencia de la lente y filmamos algunos fragmentos [...] Esa fue mi entrada en el cine documental: como legítimo instrumento de reproducción para mi tesis doctoral. Necesitaba comunicar con imágenes lo que no se creía por escrito o dibujado. El cine funcionó como Marey quería que funcionara: como documento científico de la realidad de la naturaleza" ${ }^{\prime 18}$. Velo se había licenciado en Ciencias Naturales en 1932 y obtuvo, a continuación, una beca de investigación en el laboratorio de Entomología del Museo de Ciencias Naturales de Madrid, bajo la dirección de Cándido Bolívar.

De aquella colaboración entre Velo y Zúñiga surgió, posteriormente, un corto documental que concluiría el segundo y que tituló La aventura de los Apidos Apis, de

\footnotetext{
${ }^{17}$ Este testimonio de Fernández Zúñiga está recogido en Concha AMIGO, "La situación del cine científico en España es para llorar", en Cinevídeo 20, junio-julio 1982. La importante labor de este pionero se aborda también en Ysmael ÁLVAREZ RODRÍGUEZ, op. cit., pp. 487 y ss.

${ }^{18}$ Alberto GARCÍA FERRER, "De memoria: Carlos Velo", en Cuadernos Hispanoamericanos, no 410, agosto, 1984. También hay referencia a esta tesis en una entrevista que concedió a la revista Nuestro Cine: Manuel PÉREZ ESTREMERA y Augusto M. TORRES, "Carlos Velo", en Nuestro Cine, no 63, julio 1967. Sin citar expresamente dicha tesis, relata sus trabajos de investigación apoyándose en filmaciones cinematográficas en otra entrevista recogida en: José ROVIROSA, Miradas a la realidad. Ocho entrevistas con documentalistas mexicanos, México D.F., U.N.A.M., 1990, p. 21. Asimismo, en Alberto MíGUEZ, "Conversaciones con Carlos Velo", en Índice, no 225, noviembre 1967. También merece la pena la consulta del artículo de Luis ÁLVAREZ POUSA, "As orixes ideológicas, intelectuais e artísticas do científico e cineasta Carlos Velo", en Estudos de Comunicación, Consello da Cultura Galega, $\mathrm{n}^{\circ}$ 3-4, 2005. También se encontrará información en mi libro: Fernando REDONDO NEIRA, Carlos Velo. Itinerarios do documental nos anos trinta, A Coruña, CGAI / Festival Internacional de Cine de Ourense, 2004.
} 
cuya existencia sólo quedan, también, unas pocas referencias, donde puede rastrearse, a su vez, estas primeras experiencias en la realización de un cine científico ${ }^{19}$.

De Fernández Zúñiga, iniciador del cine científico en España y fundador de Asociación Española de Cine e Imagen Científicos (ASECIC, www.asecic.org), conviene destacar la definición, altamente clarificadora, que ofrece de su campo de actuación: "No es más que el cine aplicado a la investigación de un fenómeno científico. Por extensión, los documentos se utilizan en la enseñanza dando lugar al cine didáctico y al cine de divulgación, si se hace extensivo a un mayor sector del público"20. Añade en esta misma entrevista que no puede desligarse el cine de la ciencia, una unión nacida de la necesidad de los investigadores que necesitan registrar aquellos fenómenos que estudian de una manera fidedigna y automática.

En estos años dorados de la II República, ciencia, cine y universidad unieron sus fuerzas de la mano de investigadores y docentes como Enrique Rioja Lo Bianco, quien era, entre sus muchos cargos académicos, Catedrático de Zoología de la Universidad de Madrid, tal como recoge Luis Enrique Otero Carvajal en su recuento de los científicos en el exilio ${ }^{21}$. Catedrático de Ciencias Naturales en el Instituto San Isidro, de Madrid, y consejero de Instrucción Pública, de él afirma el historiador de la pedagogía Eugenio Otero Urtaza que introdujo la cinematografía en la didáctica de la biología ${ }^{22}$. Y le menciona también Luis Gómez Mesa, siempre atento a este tipo de iniciativas que dignifican el medio cinematográfico al aportar nuevos servicios a la sociedad. Afirma este crítico e historiador que Rioja Lo Bianco pronunció una serie de conferencias con el título de "La aplicación del cinema a las Ciencias Naturales", ilustradas con la proyección de películas diversas de la biología de los animales microscópicos, de ejemplares de aves marinas, de geología, de volcanes, etc. ${ }^{23}$ De otro eminente científico de los años treinta, y que también habría de tomar el camino del exilio, Pío del Río Hortega, ha dicho Ysmael Álvarez, gran conocedor del cine científico en España, que

\footnotetext{
19 Principalmente, en las obras que Miguel Anxo FERNÁNDEZ dedicó a Velo: Carlos Velo. Cine e exilio, Vigo, Edicións A Nosa Terra, 1996, p. 44; As imaxes de Carlos Velo, Vigo, Promocións Culturais Galegas, 2002, p.19.

${ }^{20}$ Concha AMIGO, op. cit.

${ }^{21}$ Luis Enrique OTERO CARVAJAL, "La destrucción de la ciencia en España. Las consecuencias del triunfo militar de la España franquista", en Historia y Comunicación Social, $\mathrm{n}^{\mathrm{0}}$ 6, Universidad Complutense, Madrid, 2001. También puede leerse este artículo en la siguiente dirección electrónica: http://www.ucm.es/BUCM/revistasBUC/portal/modulos.php?name=Revistas2_Historico\&id=HICS\&nu= HICS010111.

${ }^{22}$ Eugenio OTERO URTAZA, Las Misiones Pedagógicas: una experiencia de educación popular, Sada, Edicións do Castro, 1982, p. 38.

${ }^{23}$ Luis GÓMEZ MESA, op. cit., p. 6
} 
mostró el movimiento de las células de micoglia con ayuda de las primeras películas aplicadas a la investigación histológica, disciplina médica de la que era un experto ${ }^{24}$.

Cabe destacar, como conclusión, que casi todos los cineastas y científicos citados hasta aquí participaron activamente en una de las experiencias pedagógicas más interesantes y novedosas del pasado siglo: las Misiones Pedagógicas. Creadas por el gobierno de la República en 1931, estaban integradas por profesores y estudiantes universitarios que recorrían los pueblos de la España rural ocupados en la divulgación de la cultura y en la promoción de la enseñanza. Las proyecciones cinematográficas eran una de las actividades más atractivas de su programa educativo ${ }^{25}$. Recordemos entonces que Enrique Rioja Lo Bianco formó parte del Patronato de Misiones Pedagógicas y participó en la primera de ellas, que tuvo lugar en diciembre de 1931 en el pueblo segoviano de Ayllón. Allí estuvo también, en representación de la Federación Universitaria Escolar (F.U.E.), Carlos Velo. Guillermo Zúñiga estuvo a cargo de la sección de cine de las Misiones, en la que compartió responsabilidades con Gonzalo Menéndez Pidal y otros cineastas como José Val del Omar o Cecilio Paniagua. El cine fue, por tanto, uno de los puentes más sólidos que se levantó entre el mundo de los intelectuales y la universidad y aquella España rural culturalmente empobrecida, con la pretensión de cumplir, de este modo, con una de las ambiciones de la II República que no era otra que la dignificación, la modernización y la regeneración social.

\footnotetext{
${ }^{24}$ Ysmael ÁLVAREZ RODRÍGUEZ, op. cit., p. 495.

25 Una nota del diario El Sol nos pone sobre la pista sobre la importancia otorgada a los modernos medios de comunicación social en su posible aplicación a la enseñanza: "Ha celebrado sesión la Comisión de Misiones Pedagógicas tratando, entre otros asuntos, de la implantación en las escuelas nacionales de la 'radio' y el 'cine', designando los vocales que han de llevar a cabo tan valiosos medios educativos e instructivos" (El Sol, 30-VIII-1931).
} 
BIBLIOGRAFÍA:

ALVAR, M.F., Cinematografía pedagógica y educativa, Madrid, J.M. Yagües, 1936.

ÁLVAREZ POUSA, Luis, “As orixes ideológicas, intelectuais e artísticas do científico e cineasta Carlos Velo", en Estudos de Comunicación, Consello da Cultura Galega, nº 3-4, 2005.

ÁLVAREZ RODRÍGUEZ, Ysmael, "Cine científico", en VV.AA., Historia del cortometraje español, Alcalá de Henares, Festival de Cine de Alcalá de Henares, 1996 , p. 492.

AMIGO, Concha "La situación del cine científico en España es para llorar", en Cinevídeo 20, junio-julio 1982.

ARMIDA Sotillo, José, "Luis Buñuel, Giménez Caballero y el Cine Club de La Gaceta Literaria”, en Turia, n 20, junio 1992.

BLANCO CASTILLA, F., El cinema educativo y Gracián pedagogo, Madrid, Francisco Beltrán, 1933.

BRIAN MORRIS, C., La acogedora oscuridad. El cine y los escritores españoles (1920-1936), Córdoba, Junta de Andalucía / Filmoteca de Andalucía, 1993.

CAPARRÓS LERA, José Ma " "Guillem Díaz-Plaja, introductor del cinema a la Generalitat', en D’Art, no 11, marzo 1985.

, "La enseñanza de la Historia del Cine en la Universidad española", en Anthropos, $\mathrm{n}^{\circ}$ 58, 1986.

DE TORRE, Guillermo, "Cinema", en Revista de Occidente, $\mathrm{n}^{\mathbf{0}}$ 34, abril, mayo y junio 1926.

DEL POZO ANDRÉS, María del Mar, "El cine como medio de alfabetización y de educación popular. Primeras experiencias", en Sarmiento. Anuario Galego de Historia da Educación, nº 1, 1997.

DÍAZ-PLAJA, Guillermo, El engaño a los ojos (Notas de estética menor), Barcelona, Destino, 1943.

, Obras selectas. Viejas memorias mías. Barcelona, Carrogio AHR, 1973.

ESCUDERO, José María, Cine Español, Madrid, Rialp, 1962. 
ESPINA, Antonio, "Reflexiones sobre cinematografía", en Revista de Occidente, T. XV (enero-marzo, 1927). Incluido en Lo cómico contemporáneo y otros ensayos, Madrid, Cuadernos Literarios, 1928.

FERNÁNDEZ, Miguel Anxo, Carlos Velo. Cine e exilio, Vigo, Edicións A Nosa Terra, 1996.

, As imaxes de Carlos Velo, Vigo, Promocións Culturais Galegas, 2002.

GARCÍA FERRER, Alberto, "De memoria: Carlos Velo", en Cuadernos Hispanoamericanos, $\mathrm{n}^{\circ}$ 410, agosto, 1984.

GIL, Rafael, "Cine documental y educativo", en Popular Film, n' 264, 3-IX1931.

GÓMEZ MESA, Luis, España en el mundo sin fronteras del cinema educativo, Madrid, Unión Iberoamericana, 1935.

GUBERN, Román, Proyector de luna. La generación del 27 y el cine. Barcelona, Anagrama, 1999.

HERRERO ORTIGOSA, Miguel "El cine pedagógico en el mundo", Revista Española de Pedagogía, no 34, abril-junio 1951.

MíGUEZ, Alberto, "Conversaciones con Carlos Velo", en Índice, $\mathrm{n}^{\circ}$ 225, noviembre 1967.

OTERO CARVAJAL, Luis Enrique, "La destrucción de la ciencia en España. Las consecuencias del triunfo militar de la España franquista", en Historia y Comunicación Social, nº 6, Universidad Complutense, Madrid, 2001.

OTERO URTAZA, Eugenio, Las Misiones Pedagógicas: una experiencia de educación popular, Sada, Edicións do Castro, 1982.

PÉREZ ESTREMERA, Manuel y M. TORRES, Augusto, "Carlos Velo", en Nuestro Cine, n ${ }^{\circ}$ 63, julio 1967.

PUYAL, Alfonso, "Gonzalo Menéndez Pidal o el cine como documento", en Pedro Poyato Sánchez (coordinador), El documental, carcoma de la ficción, X Congreso de la A.E.H.C., Córdoba, Filmoteca de Andalucía, 2004, p.169.

REDONDO NEIRA, Fernando, Carlos Velo. Itinerarios do documental nos anos trinta, A Coruña, CGAI / Festival Internacional de Cine de Ourense, 2004. 
ROVIROSA, José, Miradas a la realidad. Ocho entrevistas con documentalistas mexicanos, México D.F., U.N.A.M., 1990.

SANTOS, Mateo, "El cinema al servicio de las ideas", en Popular Film, n’ 257, 16-VII-1931.

SLUYS, Alexis, Cinematografía escolar y post-escolar, Madrid, Ed. de la Lectura, 1925.

VELA, Fernando, "Desde la ribera oscura (para una estética del cine)", en Revista de Occidente, $\mathrm{n}^{\circ}$ 23, mayo 1925, incluido en el libro El arte al cubo y otros ensayos, Madrid, Cuadernos Literarios, 1927. 